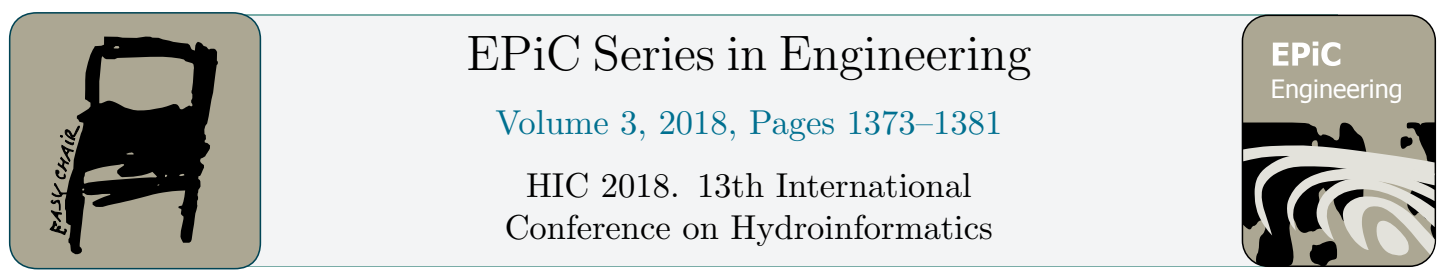

\title{
Changes in Precipitation-Runoff Relationship in Six Catchments of the Adriatic Coast of Central Italy
}

\author{
Francesco Memmola and Giovanna Darvini \\ Università Politecnica delle Marche, via Brecce Bianche, Ancona 60131, Italy \\ f.memmola@univpm.it
}

\begin{abstract}
Besides climate change, human activities may introduce variability in the flow regime. Thus, investigation of the impacts of climate change and human activity on hydrology recently has become an important issue. In this paper hydrological data of six catchments in the coastal area of the Adriatic sea, in central Italy, were used to detect statistically significant trends and change points in annual rainfall and streamflow. Moreover, potential changes in precipitation-runoff relationship have been investigated and finally a quantitative evaluation of the effect of climate variability and human activities on runoff has been assessed separately, with the former individuated as the more influent.
\end{abstract}

\section{Introduction}

The climate system warming is worldwide recognized, with observed changes since 1950s without precedents over decades to millennia [9]. Observed changes in global annual precipitation from 1951 to 2010 indicate a significant increment in precipitation in North America, part of the South America (especially Argentine) part of northern and central Asia, India, northern Europe and Australia. Conversely, a reduction is detected in the Mediterranean area, southern and central Africa and the east part of central Asia [9]. Climate change impacts on human systems are often spatially heterogeneous because their variability rises not just from the climate change itself, but also from social and economic factors [9]. Hence, the changes are more easily observed at local levels. This is especially true for precipitation which are strongly dependent on atmospheric circulation and on the local orography [13] .One of the most important consequences of climate change is represented by the potential alteration of hydrological cycles [4]. In many regions changes in precipitation or melting snow and ice are altering hydrological systems with effects in water resources in terms of quantity and quality [9]. In addition to global climate change also human activities such as irrigation, cultivation, afforestation, deforestation and urban construction may introduce variability in the flow regime. An example is the reduction in streamflow due to afforestation [2]. Furthermore land use such us irrigation and terraces can lead to change in water cycle and runoff [7].Thus, investigation of the impacts of climate change and human activity on hydrology and water resources, recently has become a considerate concerns. Detection of individual effects of climate change and human activities on hydrological regime is a challenge which needs to be studied on a local scale. In last years many works concerning the 


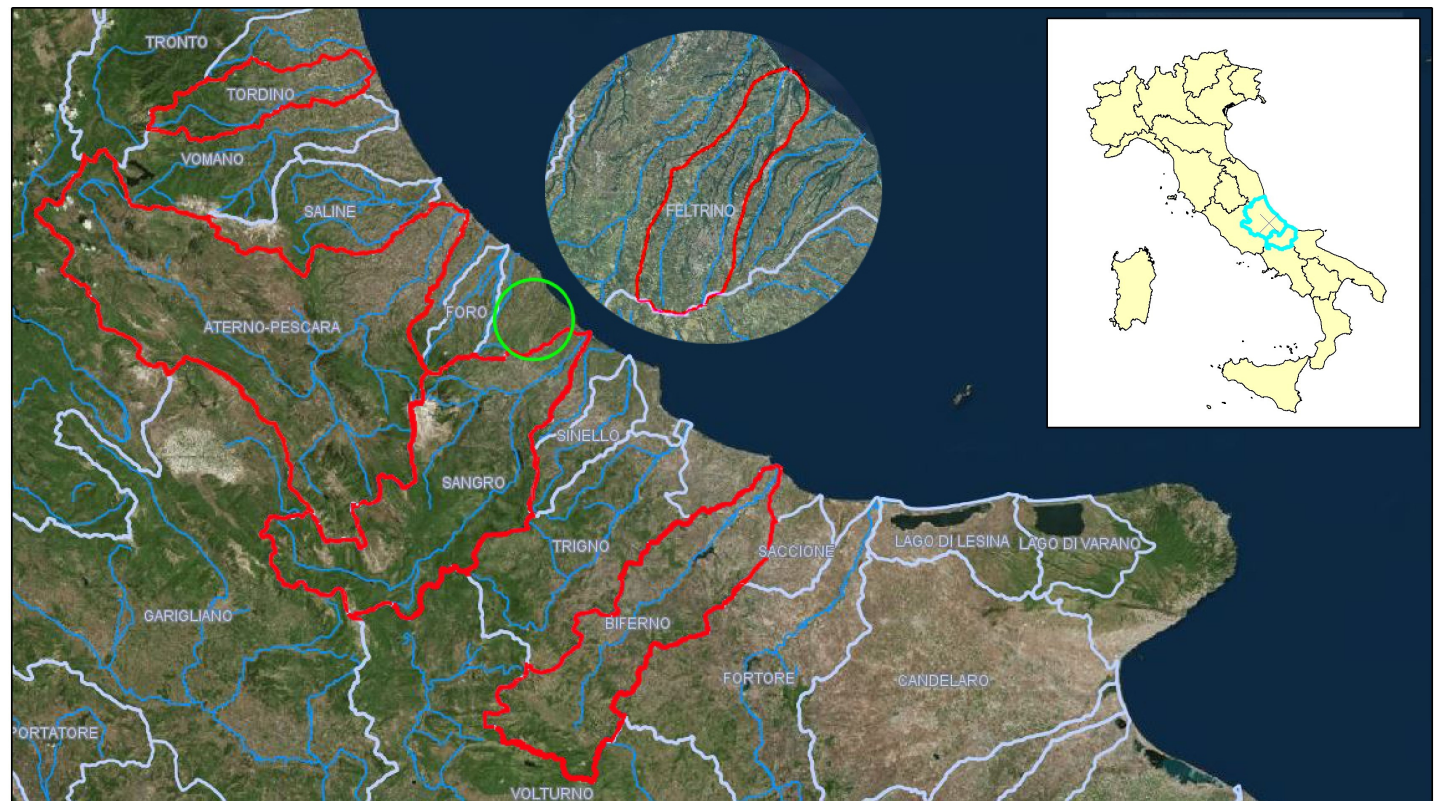

Figure 1: Map showing the location of the six catchments (red curves). From North to South: Tordino, Pescara, Feltrino (green circle), Sangro and Biferno (Extracted from Ministero dell'Ambiente Geoportale Nazionale)

possible impact of climate change on rivers runoff were carried out, however, to what concern our knowledge, quantifying systematically the relative contributions of climatic variability and human activities to runoff change in any italian river basin has not been reported. In this paper hydrological data of six catchments of rivers located in the Abruzzo region (with the exception of the Biferno which is located in the Molise region) and flowing in the Adriatic sea (Figure 1 ) were analysed. This coastal area is important for its natural ecosystems but also for the related recreational and economic activities. However the salinity [1] and the eutrophication [5] of these coastal waters are influenced by river runoff with obvious repercussions on this delicate environment. In this framework the objectives of our study are (1) to detect statistically significant trends and change points in annual precipitation and streamflow, (2) to discover changes in precipitation-runoff relationship and (3) to estimate the proportion of streamflow change attributing to climatic and human activities influence.

\section{Methodology}

\subsection{Trend detection and break point analysis method}

The rank-based Mann-Kendall test [8, 6] has been used in order to detect trends in precipitation and streamflow time series. This test has the advantage to do not require the data to be normally distributed, it is not strongly affected by the presence of outliers and has the same power as its parametric competitors. Trends magnitude was estimated by the Sen's slope method [12] based on Kendall's tau. 
The double mass curve (DMC) frequently used to detect hydrological changes caused by human activities, is the plot of the accumulate values of one variable against the accumulate values of another related variable for a concurrent period. It is a straight line if two variables are proportional, with the slope of the line representing the ration between the two variables. A change in the line slope may indicate the broken of the original relationship. In this study, DMC between precipitation and runoff was used as an auxiliary tool for the confirmation of the change points.

The Pettitt's test [10] is a non-parametric approach to determine the occurrence of a change point. This test is distribution-free and rank-based method for detecting a significant change point in time series, when the exact time of the change is unknown. The significant differences between means of two samples were tested using the two tails t-test with a $95 \%$ confidence level.

\subsection{Separation of climate and human activities effects on streamflow change.}

\subsubsection{General framework}

The streamflow of a certain catchment calculated as a function of climate variables and human activities $[16,14]$ is

$$
Q=f(C, H)
$$

where $Q$ is the streamflow, $C$ the climate factors influencing the stremflow and $H$ the factor representing the impact of human activities on streamflow. Thus, from equation (1), the change in streamflow can be calculated as follow

$$
\Delta Q=f_{c}^{\prime} \Delta C+f_{h}^{\prime} \Delta H
$$

with $\Delta Q, \Delta C$ and $\Delta H$ being changes in streamflow, climate and human activities, respectively and $f_{c}^{\prime}=\frac{\partial Q}{\partial C}$ and $f_{h}^{\prime}=\frac{\partial Q}{\partial H}$. With a first-order approximation, equation (2) becomes [15, 14]

$$
\Delta Q=\Delta Q_{c}+\Delta Q_{h}
$$

where $\Delta Q_{c}$ and $\Delta Q_{h}$ are changes in streamflow due to climate change and human activity respectively. In the presence of a change point, $\Delta Q$ can be estimated by subtracting the observed average streamflow before the change point $Q_{b}^{o}$ from the observed average annual streamflow during the changed period $Q_{a}^{o}$. As a result, the separation of the effect of climate change from that of human activities can be obtain if ones either $\Delta Q_{c}$ or $\Delta Q_{h}$ is known [14]

\subsubsection{The climatic elasticity model}

In this study we estimate the effect of climate change on streamflow using the climate elasticity method first proposed by [11] and afterwards developed by several authors (e.g. [3, 16]). The elasticity of runoff can be defined by the proportional change of streamflow against the proportional change of a climate factor. Following [16], the precipitation elasticity of runoff can be expressed as

$$
\varepsilon_{p}=\frac{\Delta Q_{i} / \bar{Q}}{\Delta P_{i} / \bar{P}}
$$

where $\Delta P_{i}$ and $\Delta Q_{i}$ are changes of the annual precipitation and streamflow with respect to the long-term average of precipitation $(\bar{P})$ and runoff $(\bar{Q})$. The $\varepsilon_{p}$ can be estimated from the observed runoff and precipitation during the period before the change point. After the change point, the runoff annual changes can be estimated rearranging equation (4). 


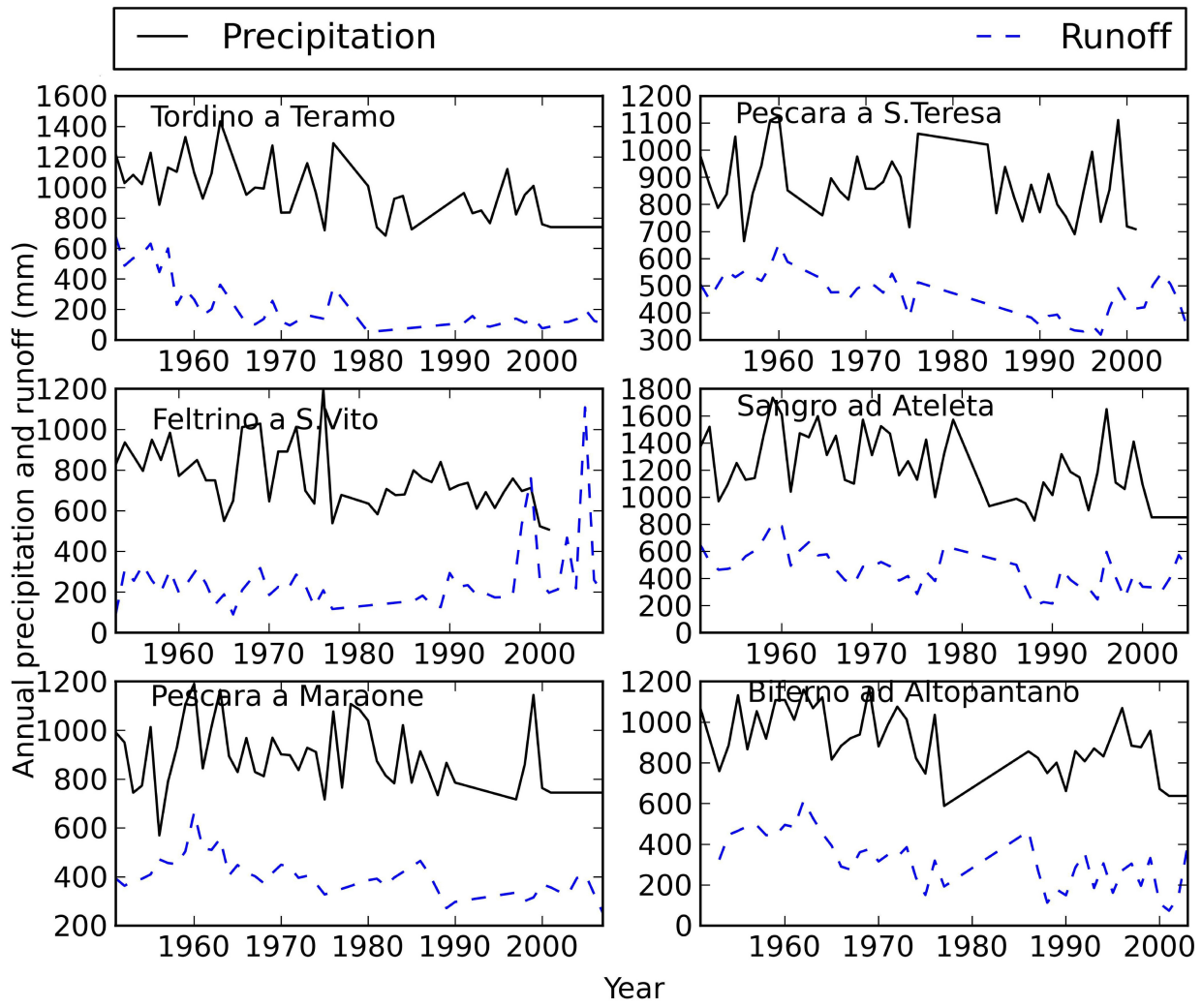

Figure 2: Annual precipitation and runoff time series in the six catchments of the Abruzzo and Molise regions

\subsection{Dataset}

The rainfall and runoff dataset refers to the historical series collected in the hydrographic basins of the rivers Tordino, Pescara, Feltrino and Sangro in the Abruzzo region and Biferno in the Molise region. The data have been selected from the database of Centro Funzionale e Ufficio Idrografico Regione Abruzzo. The period of observation for the daily rainfall is the interval 1951-2007, however more recent data have been requested and maybe they will be available soon. In this first glance missing data were not taken into account.

\section{Results and Discussion}

\subsection{Observed trends and change points analysis}

Observed annual precipitation and runoff in the six catchments during the period of 1951-2007 are presented in Figure 2. In Table 1 the statistical results of trends in precipitation and runoff based on Mann-Kendal test are presented. With the exception for the runoff of the Feltrino a S.Vito, annual precipitation and annual runoff presented clear downward trends in all the 
Table 1: Summary of trend analysis for annual precipitation and runoff by Mann-Kendall test

\begin{tabular}{lcccccc}
\hline & \multicolumn{3}{c}{ Annual precipitation } & \multicolumn{3}{c}{ Annual runoff } \\
\hline Catchments & z-test & Significance & Slope & z-test & Significance & Slope \\
\hline Tordino a Teramo & -4.46 & $* * *$ & -6.71 & -4.50 & $* * *$ & -4.70 \\
Pescara a S.Teresa & -1.58 & ns & -2.20 & -3.44 & $* * *$ & -2.52 \\
Feltrino a S.Vito & -3.34 & $* * *$ & -4.64 & 0.20 & ns & 0.11 \\
Sangro ad Ateleta & -3.60 & $* * *$ & -7.61 & -3.93 & $* * *$ & -4.74 \\
Pescara a Maraone & -2.87 & $* *$ & -2.96 & -4.15 & $* * *$ & -2.30 \\
\hline
\end{tabular}

*** and $* *$ indicate confidence level of $99 \%$ and $95 \%$ respectively; ns indicates confidence level under $95 \%$

Table 2: Summary for the annual runoff change points analysis

\begin{tabular}{|c|c|c|c|c|c|c|c|c|}
\hline & \multicolumn{2}{|c|}{ Change point } & \multicolumn{5}{|c|}{ Pre-change period Post-change period } & \\
\hline Catchments & year & Significance & Mean & $\mathrm{Cv}$ & Mean & $\mathrm{Sd}$ & $\mathrm{Cv}$ & Change (\%) \\
\hline Tordino a Teramo & 1963 & **** & $427.97 \quad 181.73$ & 0.42 & 140.92 & 70.63 & 0.50 & 67.07 \\
\hline Pescara a S.Teresa & 1974 & ** & $520.79 \quad 49.39$ & 0.09 & 413.94 & 68.19 & 0.16 & 20.52 \\
\hline Feltrino a S.Vito & 1997 & $\mathrm{~ns}$ & $211.62 \quad 66.07$ & 0.31 & 400.40 & 298.44 & 0.75 & 89.21 \\
\hline Sangro ad Ateleta & 1972 & ** & 556.78116 .60 & 0.21 & 386.45 & 115.5 & 0.30 & 30.59 \\
\hline Pescara a Maraone & 1973 & $* * *$ & 446.7070 .31 & 0.16 & 354.96 & 50.34 & 0.14 & 20.54 \\
\hline Biferno ad Altopantano & 1974 & $* * *$ & $419.33 \quad 88.97$ & 0.21 & 242.94 & 104.76 & 0.43 & 42.06 \\
\hline
\end{tabular}

Change point from Pettit's test. ${ }^{* * *}$ and ${ }^{* *}$ indicate confidence level of $99 \%$ and $95 \%$ respectively; ns indicates confidence level under 95\%. Sd, standard deviation; Cv coefficient of variation

catchments. With slope at rates from -2.96 to -7.61 for the precipitation and rates from -2.30 to -6.07 for the runoff. However the trend detected for the precipitation in Pescara a S.Teresa catchment is not statistically significant. The DMC method (3) was used to further investigate the change points of runoff series. The relationships between precipitation and runoff can be represented nearly by two straight lines with different slope before and after 1963 for the Tordino a Teramo catchment, before and after 1972 for the Sangro ad Ateletta catchment, before and after 1973 for the Pescara a Maraone and Biferno ad Altopantano catchments, before and after 1974 for the Pescara a S.Teresa catchment and before and after 1997 for the Feltrino a S.Vito catchment. This may be interpreted as an abrupt change in the runoff series. Since DMC test is sensible to change not related with precipitation, this implies that runoff might be affected by other factors such as human activities. The Pettitt's test was also used to detect the change points in runoff series. The results by Pettitt's test are in good agreement with the change points detected by DMC method, with the exception for the Tordino a Teramo and Biferno ad Altopantano catchment. According with the change points listed in Table 2, time series for all the catchments were split into two period: a pre-change period and a post-change period. 

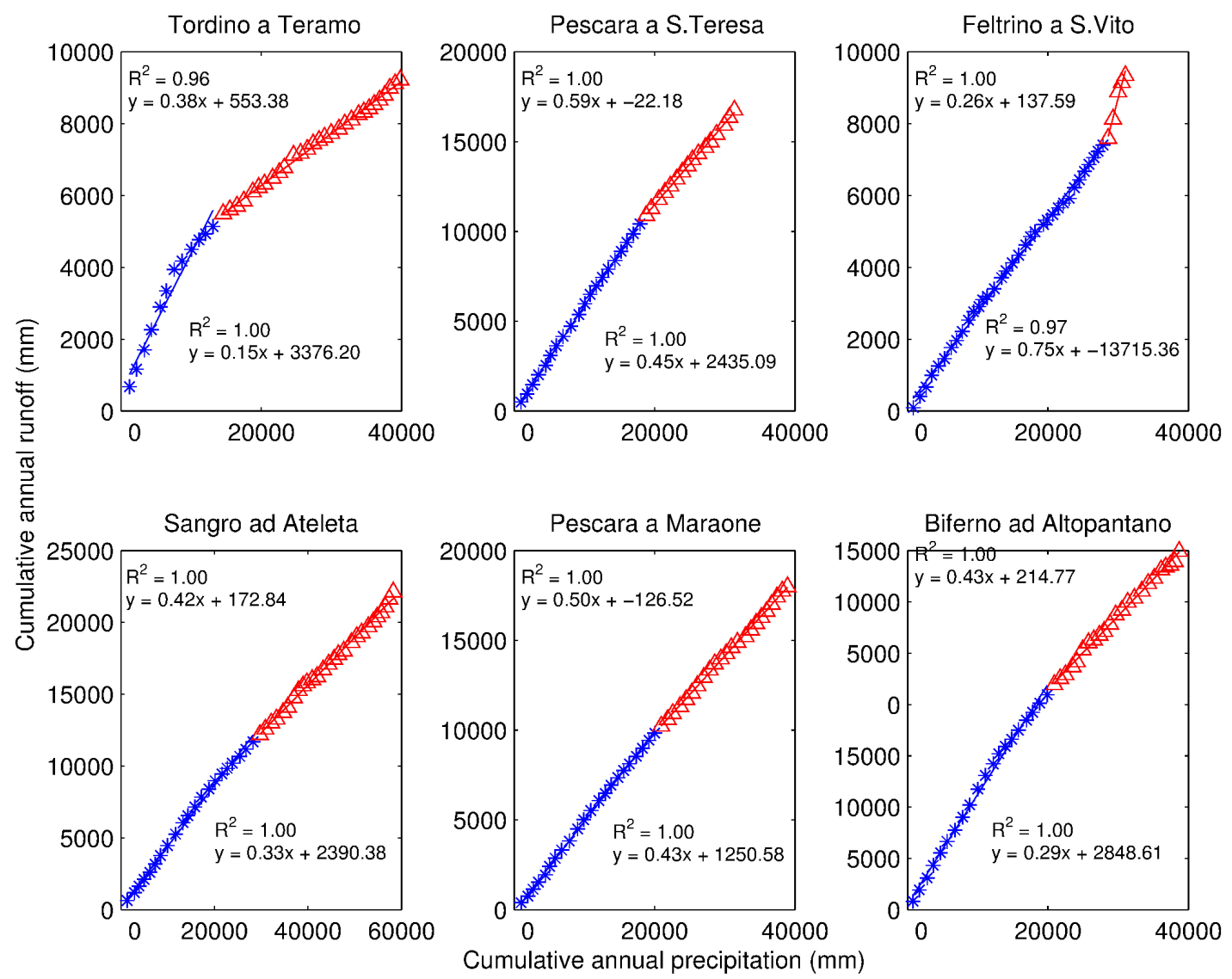

Figure 3: Double mass curve of annual precipitation and runoff for the six catchments of Abruzzo and Molise regions

\subsection{Precipitation and runoff relationship}

The means and standard deviation (Table 2) of the annual runoff during the pre-change and post-change periods are analysed in order to understand the feature of the runoff change. With the exception of the Feltrino a S.Vito catchment, in all the others catchments the mean annual runoff decreased during the post change period. The significant differences between the means of the two samples during the pre-change period and the post-change period was found performing a t-test with a $95 \%$ confident level. The coefficient of variation $(\mathrm{Cv})$ for all the six catchments are listed in Table 2. In five of them the coefficient of variation was higher when calculate during the post-change period indicating more variations during this period. Furthermore the relationship between precipitation and runoff (Figure 3) was also investigate. The slope of the linear regression was higher during the pre-change period exept for Pescara a S.Teresa and Feltrino a S.Vito; however, for this two catchments, some statistical analysis were not significant (see Table 2). The fact that the regression lines for the post-change period in four catchments lie below that for the pre-change period means that in post-change period, the same annual precipitation in the pre-change period produces less runoff, suggesting that runoff 

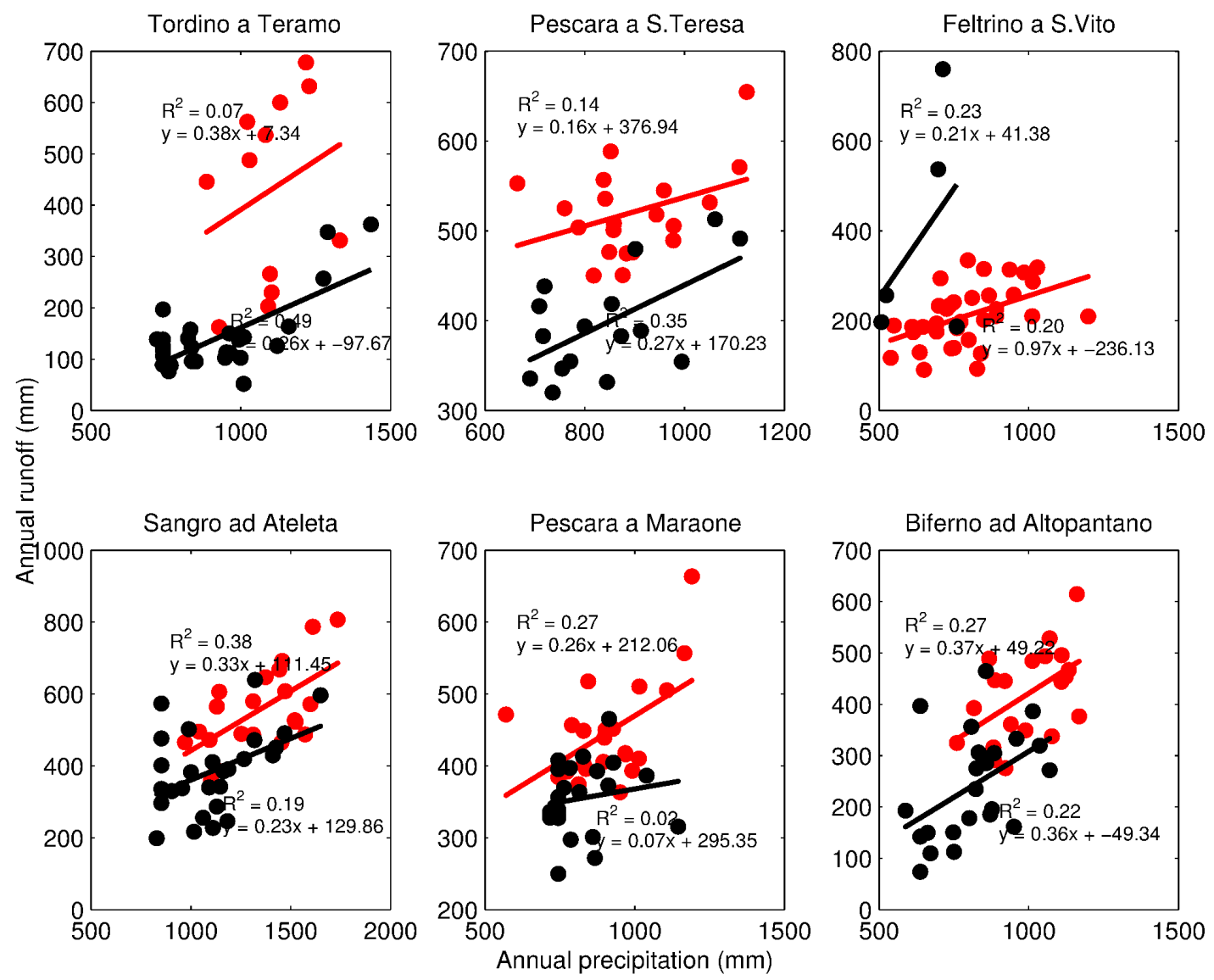

Figure 4: Correlation between precipitation and runoff for pre-change period (red line) and post-change period (black line)

Table 3: Precipitation elasticity and effects of climate variability and human activity on mean annual runoff for post-change period

\begin{tabular}{lcccc}
\hline Catchments & $\varepsilon_{p}$ & $R^{2}$ & $\Delta Q_{c}(\%)$ & $\Delta Q_{h}(\%)$ \\
\hline Tordino a Teramo & 1.66 & 0.07 & 77.61 & 22.39 \\
Pescara a S.Teresa & 0.28 & 0.13 & 55.79 & 44.21 \\
Feltrino a S.Vito & 0.79 & 0.28 & 22.87 & 122.87 \\
Sangro ad Ateleta & 0.87 & 0.38 & 76.13 & 23.87 \\
Pescara a Maraone & 0.56 & 0.27 & 63.28 & 36.72 \\
Biferno ad Altopantano & 1.13 & 0.34 & 73.08 & 26.92 \\
\hline
\end{tabular}


is also affected by increased human activities in the study area.

\subsection{Elasticity climate model and climate and human activities impact on runoff}

Taking the Tordino a Teramo catchment as an example, regarded as the slope in the linear regression model of the change of runoff against the change of precipitation in Equation 4, the precipitation elasticity $\varepsilon_{p}$ is estimated to be 1.66 indicating that a $10 \%$ change in precipitation will cause an $16.6 \%$ change in runoff. The precipitation elasticity of six catchments was calculated and listed in Table 3. For all the catchments, the climate elasticity method provided estimates of the changes in runoff for post-change period due to climate variability and, as a consequence, due to human activities. Climate variability is the dominant factor for runoff change across all the catchments except for Feltrino a S.Vito. The results for the latter have been reported here for seeking of completeness however it should be kipped in mind that both change point analysis and trend analysis for precipitation are not significant.

\section{Conclusions}

Statistical analysis was used to detect trends and change points in precipitation and runoff time series in six catchments in the Abruzzo and Molise regions. Remarkable downward trends in runoff can be found in five catchments of rivers flowing in the Adriatic sea. The same trends have been observed for the precipitation in all the catchments however, the trend was not significant in the Pescara a S.Teresa catchment. This implies that runoff in this rivers is affected by precipitation which is in good agreement with what found for the Mediterranean area by [9]. According to change points detected in runoff, the study period for all the catchments can be divided into two periods, a pre-change period, when few human activities affect runoff, and a post-change period. Except the Feltrino a S.Vito, significant change point where detected in all the catchments with the post-change period characterized by a decrease in river runoff. The climate elasticity method was also used to separately assess the anthropic impact and climate change on runoff. Despite the predominance of the climate impact, also human activities influence the runoff change. In this work we present a first evaluation of the individual effect of human activities and climate change on river runoff in some Italian rivers; however there are uncertainties due to the methodology chosen and the dataset used. It must be noted that the framework used to estimate proportional contribution of climate variability and human activities to runoff is based on the assumption that human activity is independent on climate change [16]. However, the effects of human activities and climate are inter-related with each other and are not readily separable [14]. Concerning the data used, uncertainties may arise from missing data. In a future work, these aspects will be taken into consideration and other methodology for evaluating the contribute of human activities and climate variability on change of river runoff will be applied in order to confirm and make more robust our results.

\section{Acknowledgments}

This work is fully supported by the scientific project "Building Resilience to flood Impact Deriving from Global warming in Europe (BRIDGE)" founded by Polytechnic University of Marche internal program 2017/2018. Dataset were kindly provided by Centro Funzionale e Ufficio Idrografico Regione Abruzzo. 


\section{References}

[1] Antonio Artegiani, Davide Bregant, Elio Paschini, Nadia Pinardi, Fabio Raicich, and Aniello Russo. The adriatic sea general circulation. part II: baroclinic circulation structure. Journal of physical Oceanography, 27(8):1515-1532, 1997.

[2] Alice E Brown, Lu Zhang, Thomas A McMahon, Andrew W Western, and Robert A Vertessy. A review of paired catchment studies for determining changes in water yield resulting from alterations in vegetation. Journal of hydrology, 310(1-4):28-61, 2005.

[3] JCI Dooge, M Bruen, and B Parmentier. A simple model for estimating the sensitivity of runoff to long-term changes in precipitation without a change in vegetation. Advances in Water Resources, 23(2):153-163, 1999.

[4] Thomas G Huntington. Evidence for intensification of the global water cycle: review and synthesis. Journal of Hydrology, 319(1):83-95, 2006.

[5] Cristina Ingarao, Giovanna Lanciani, Carmen Verri, and Tommaso Pagliani. First record of prorocentrum lima (dinophyceae) inside harbor areas and along the abruzzo region coast, w adriatic. Marine pollution bulletin, 58(4):596-600, 2009.

[6] Maurice G Kendall. Rank correlation methods. Griffin: London, UK, 1975.

[7] Zhenmei Ma, Shaozhong Kang, Lu Zhang, Ling Tong, and Xiaoling Su. Analysis of impacts of climate variability and human activity on streamflow for a river basin in arid region of northwest china. Journal of Hydrology, 352(3-4):239-249, 2008.

[8] Henry B Mann. Nonparametric tests against trend. Econometrica: Journal of the Econometric Society, pages 245-259, 1945.

[9] Rajendra K Pachauri, Myles R Allen, Vicente R Barros, John Broome, Wolfgang Cramer, Renate Christ, John A Church, Leon Clarke, Qin Dahe, Purnamita Dasgupta, et al. Climate change 2014: synthesis report. Contribution of Working Groups I, II and III to the fifth assessment report of the Intergovernmental Panel on Climate Change. IPCC, 2014.

[10] AN Pettitt. A non-parametric approach to the change-point problem. Applied statistics, pages 126-135, 1979.

[11] John C Schaake. From climate to flow. Climate change and US water resources., pages 177-206, 1990.

[12] Pranab Kumar Sen. Estimates of the regression coefficient based on kendall's tau. Journal of the American statistical association, 63(324):1379-1389, 1968.

[13] Luciano Soldini and Giovanna Darvini. Extreme rainfall statistics in the marche region, italy. Hydrology Research, 48(3):686-700, 2017.

[14] Weiguang Wang, Quanxi Shao, Tao Yang, Shizhang Peng, Wanqiu Xing, Fengchao Sun, and Yufeng Luo. Quantitative assessment of the impact of climate variability and human activities on runoff changes: a case study in four catchments of the haihe river basin, china. Hydrological Processes, 27(8):1158-1174, 2013.

[15] Xiaoping Zhang, Lu Zhang, Jing Zhao, Paul Rustomji, and Peter Hairsine. Responses of streamflow to changes in climate and land use/cover in the loess plateau, china. Water Resources Research, 44(7), 2008.

[16] Hongxing Zheng, Lu Zhang, Ruirui Zhu, Changming Liu, Yoshinobu Sato, and Yoshihiro Fukushima. Responses of streamflow to climate and land surface change in the headwaters of the yellow river basin. Water Resources Research, 45(7), 2009. 